\title{
Critical Role of Connexin 43 in Secondary Expansion of Traumatic Spinal Cord Injury
}

\author{
Chunlan Huang, ${ }^{1 \star}$ Xiaoning Han, ${ }^{1 \star} \mathrm{Xi} \mathrm{Li,}{ }^{1 \star}$ Eric Lam, ${ }^{1}$ Weiguo Peng, ${ }^{1}$ Nanhong Lou, ${ }^{1}$ Arnulfo Torres, ${ }^{1}$ Meixiang Yang, ${ }^{1}$ \\ Juan Mauricio Garre, ${ }^{2}$ Guo-Feng Tian, ${ }^{1}$ Michael V. L. Bennett, ${ }^{2}$ Maiken Nedergaard, ${ }^{1}$ and Takahiro Takano ${ }^{1}$ \\ ${ }^{1}$ Division of Glial Disease and Therapeutics, Center for Translational Neuromedicine, Department of Neurosurgery, University of Rochester, Rochester, \\ New York 14642, and 2Department of Neuroscience, Albert Einstein College of Medicine, Bronx, New York 10461
}

\begin{abstract}
Spinal cord injury (SCI) is often complicated by secondary injury as a result of the innate inflammatory response to tissue trauma and swelling. Previous studies have shown that excessive ATP release from peritraumatic regions contributes to the inflammatory response to SCI by activation of low-affinity P2X7 receptors. Because connexin hemichannels constitute an important route for astrocytic ATP release, we here evaluated the impact on post-traumatic ATP release of deletion of connexins (Cx30/Cx43) in astrocytes. In vivo bioluminescence imaging showed a significant reduction in ATP release after weight-drop injury in mice with deletion of $\mathrm{Cx} 43$ compared with Cx43-expressing littermates, both on a Cx30 knockout background. Moreover, astrogliosis and microglia activation were reduced in peritraumatic areas of those mice lacking $\mathrm{Cx} 43$; motor recovery was also significantly improved, and the traumatic lesion was smaller. Combined, these observations are consistent with a contribution by astrocytic hemichannels to post-traumatic ATP release that aggravates secondary injury and restrains functional recovery after experimental spinal cord injury. Connexins may thereby constitute a new therapeutic target in spinal cord injury.
\end{abstract}

\section{Introduction}

It is estimated that in the United States alone $\sim 400,000$ individuals are living with spinal cord injury (SCI) with more than 14,000 new cases occurring each year (Sekhon and Fehlings, 2001). Although acute inflammatory response is a defense mechanism aimed at preserving tissue integrity and demarcating the traumatic lesion (Bethea, 2000), an exaggerated response may limit the potential for successful recovery (Popovich and Longbrake, 2008). Tissue swelling, especially within the tight confines of the vertebral canal, can reduce tissue perfusion and cause secondary ischemia. The delayed loss of tissue affects functional recovery in most patients, and no effective treatment options currently exist.

It was shown 50 years ago that injection of ATP in the absence of injury was sufficient to induce acute inflammatory responses. A key observation linking purine signaling to inflammatory mediators was that activation of a purinergic receptor P2RX7 triggers maturation and secretion of IL- $1 \beta$ from microglial cells (Di Virgilio et al., 1999). Although it is recognized that adenine nucleotides (i.e., ATP and its metabolites) are inflammatory medi-

\footnotetext{
Received March 9, 2011; revised Jan. 11, 2012; accepted Jan. 13, 2012.

Author contributions: G.-F.T., M.N., and T.T. designed research; C.H., X.H., X.L., E.L., W.P., N.L., A.T., M.Y., J.M.G., and G.-F.T. performed research; M.V.L.B. contributed unpublished reagents/analytic tools; C.H., X.H., X.L., G.-F.T., M.V.L.B., and T.T. analyzed data; M.N. and T.T. wrote the paper.

This study was supported by the New York State Spinal Cord Injury Research Board and National Institutes of Health Grants T32DE007202, NS50350, and NS038073.

${ }^{*}$ C.H., X.H., and X.L. contributed equally to this work.

Correspondence should be addressed to either Takahiro Takano or Maiken Nedergaard, Division of Glial Disease and Therapeutics, University of Rochester Medical Center, 601 Elmwood Avenue, Rochester, NY 14642. E-mail: takahiro_takano@urmc.rochester.edu or nedergaard@urmc.rochester.edu.

DOI:10.1523/JNEUROSCI.1216-11.2012

Copyright $\odot 2012$ the authors $\quad 0270-6474 / 12 / 323333-06 \$ 15.00 / 0$
}

ators, the role of purinergic signaling in spinal cord injury has received relatively little attention (Cotrina and Nedergaard, 2009). We showed previously that spinal cord injury leads to excessive and sustained ATP release in peritraumatic regions and inhibition of P2RX7 reduces inflammatory responses and improves functional recovery.

Previous studies showed that astrocytes release ATP, at least in part, by the opening of connexin43 (Cx43) hemichannels (Cotrina and Nedergaard, 2009). Connexins are a family of proteins with dual channel functions (Bennett et al., 2003). The traditional role is to form gap junctions, which are composed of two docked hemichannels linking the cytosol of two neighboring cells. Gap junctions allow cell-to-cell passage of ions and small molecules, including $\mathrm{Ca}^{2+}$, $\mathrm{cAMP}, \mathrm{IP}_{3}$, ATP, glutamate, and glucose. It has been acknowledged that unopposed hemichannels constitute a pathway for regulated gliotransmitter release (Bennett et al., 2003). Because of their relatively large inner-pore diameter $(\sim 10 \AA)$, open hemichannels facilitate efflux of small cytosolic compounds, and many of these, including ATP and glutamate, will act as transmitters once released (Cotrina et al., 1998; Parpura et al., 2004). Hemichannel openings are normally tightly controlled, because prolonged opening of many hemichannels is incompatible with cellular survival. We sought here to define the role of $\mathrm{Cx} 43$ in post-traumatic ATP release and secondary injury after SCI.

\section{Materials and Methods}

Spinal cord injury and bioluminescence imaging of extracellular ATP. Knockout $\mathrm{Cx} 30$ and floxed $\mathrm{Cx} 43$ mice $\left(\mathrm{Cx} 30^{-1-}, \mathrm{Cx} 43^{\mathrm{fl} / \mathrm{fl}}\right)$ and mice expressing Cre under the human GFAP (hGFAP) promoter were obtained from Klaus Willecke's laboratory (University of Bonn, Bonn, Germany) (Theis et al., 2001). Female mice of 8-10 weeks of age (15-25 g) 
A Cx43wt

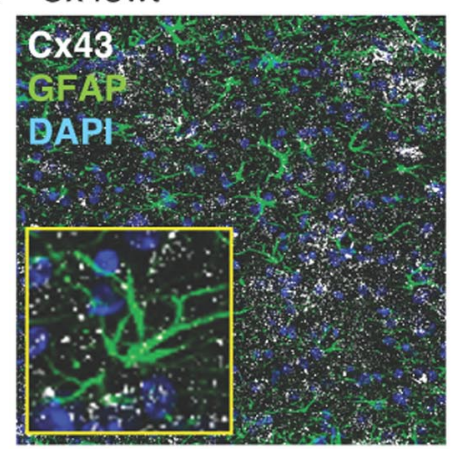

Cx43ko

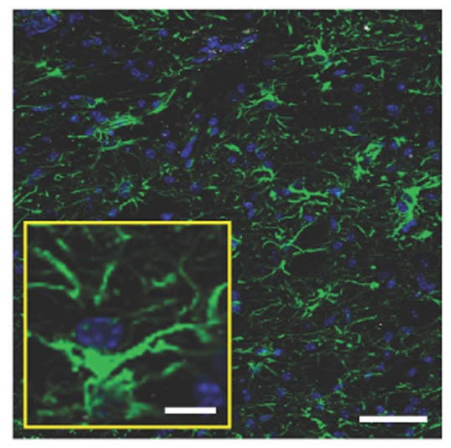

B

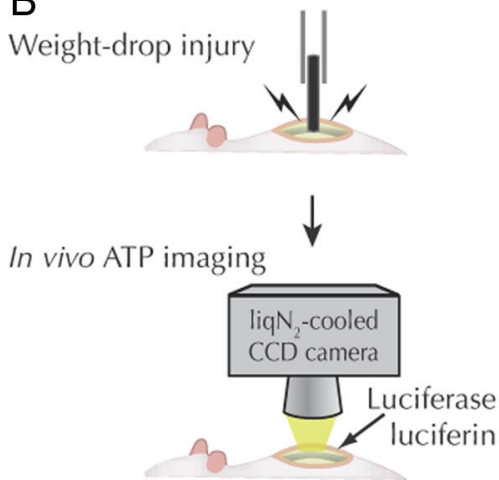

C

Cx43wt

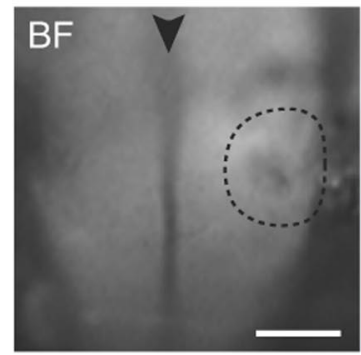

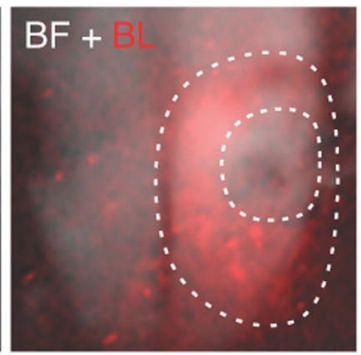

\section{Cx43ko}

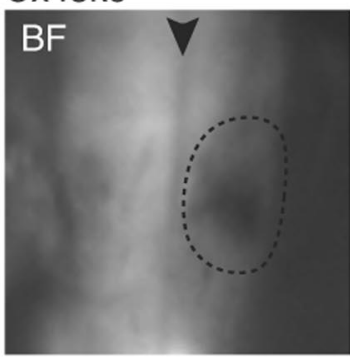

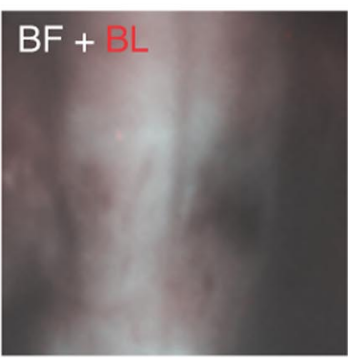

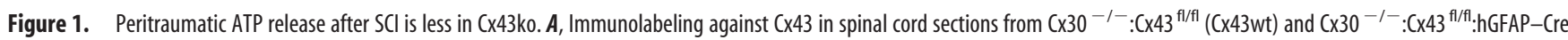
(Cx43ko) mice. Scale bar, $50 \mu \mathrm{m}$. Inserts, High-magnification images. Scale bars, $10 \mu \mathrm{m}$. B, A schematic of experimental procedure. C, Bioluminescence detection of ATP release from the exposed spinal cord of $\mathrm{Cx} 43 \mathrm{wt}$ and $\mathrm{Cx} 43 \mathrm{ko}$ mice after SCl. BF, bright-field views of dorsal side with the lesioned regions indicated by dotted lines; black arrowheads indicate dorsal spinal vein. BF + BL, Bioluminescence images (red) superimposed on bright-field images. White dotted lines indicate the area with high ATP release surrounding the lesion. Scale bar, $0.5 \mathrm{~mm}$.

were anesthetized with ketamine $(60 \mathrm{mg} / \mathrm{kg}$, i.p.) and xylazine $(10 \mathrm{mg} / \mathrm{kg}$, i.p.). A laminectomy of the dorsal portion of T11 was performed, and the vertebral column was held with fine clamps at the T10 and T12 levels. The exposed dorsal surface of the spinal cord was subjected to drop of a $3 \mathrm{~g}$ weight with flat tip (diameter $0.5 \mathrm{~mm}$ ) from a height of $12.5 \mathrm{~mm}$ (modified NYU impactor) (Peng et al., 2009). Lesions were lateral or on the midline. The Basso Mouse Scale for Locomotion (BMS) rating scale, from 0 (no ankle movement) to 9 (normal gait), was used for evaluating hindlimb movement (Basso et al., 2006; Peng et al., 2009). The mice were blindly evaluated daily at the same time for 8 weeks after injury. ATP release from the exposed spinal cord was imaged by bioluminescence (Wang et al., 2004) within $1 \mathrm{~h}$ after SCI. High ATP area was defined as the area with luminescence $>1$ standard deviation above the average luminescence of the field $>2 \mathrm{~mm}$ away from the injury.

In vivo recordings of compound action potentials. Mice were anesthetized with isoflurane (1.5-2.5\%), immobilized with pancuronium bromide $(0.3 \mathrm{mg} / \mathrm{kg}$ ), and artificially ventilated (SAR-830, CWE). A bipolar stimulating electrode (TST33A05KT, WPI) was inserted $150 \mu \mathrm{m}$ into the left dorsal column rostral to the lesion. Stimulation was delivered through an isolated constant current source (IsoFlex). A saline-filled glass recording electrode was inserted $150 \mu \mathrm{m}$ into the left dorsal column, $5 \mathrm{~mm}$ caudal from the stimulating electrode. One week after SCI, compound action potentials (CAPs) were recorded (20 $\mu$ s sampling time) by using a 700B amplifier (Molecular Devices) with pCLAMP software, and their amplitude was measured as the difference between positive and negative peaks. White matter loss was evaluated by Luxol Fast Blue $(0.1 \%)$ staining of cryosections $(20 \mu \mathrm{m})$. The dorsal column was first identified in sections located at least $1 \mathrm{~mm}$ from the lesion border, and then the column was followed on serial sections through the lesion center. The section with the most severe loss of the dorsal column was identified, and the percentage of spared axons was quantified by using ImageJ (National Institutes of Health).

Immunohistochemistry. At 1 week and 1 month after SCI, mice were perfusion fixed and vibratome sections were labeled against GFAP (1: 500, monoclonal against purified pig spinal cord GFAP, G3893, Sigma), ionized calcium binding adaptor molecule 1 (Iba1) (1:500, polyclonal against C terminus, 019-19741, Wako), or CD68 (1:100, monoclonal against ED1 clone, MCA341GA, Serotec). Six fields $\left(200 \times 200 \mu \mathrm{m}^{2}\right)$ near the lesion, one each from rostal, middle, and caudal to the lesion, left and right in gray matter, were chosen for analysis. Confocal images were taken at $1 \mu \mathrm{m}$ steps for $10 \mu \mathrm{m}$ depth and stacked together before quantification; capture parameters were set from a wild-type spinal cord and remained constant. The average intensity of GFAP and Ibal were compared with average intensity at least $5 \mathrm{~mm}$ away from the lesion in the same section, and the number of CD68 + cells in a field was counted (Peng et al., 2009). Lesion volume was quantified on serial cryosections labeled against GFAP.

Statistics. All data are expressed as mean \pm SEM. For statistical evaluations, Kruskal-Wallis test and/or Mann-Whitney test were used when normality was rejected by Shapiro-Wilk test. Otherwise, Student's $t$ test was used.

\section{Results}

To assess the effect of connexins on ATP release evoked by spinal cord injury, we used mice with loxP conditional deletion of $\mathrm{Cx} 43$ in astrocytes with Cre expression driven by the hGFAP promoter (Theis et al., 2003). Because deletion of Cx43 can induce increased expression of Cx30 (Wallraff et al., 2006; Lin et al., 2008), adult female littermates with deletion of $\mathrm{Cx} 30$ and intact $\mathrm{Cx} 43$ expression $\left(\mathrm{Cx} 30^{-/-}: \mathrm{Cx} 43^{\mathrm{fl} / \mathrm{fl}}\right.$ without hGFAP-Cre, here termed Cx43wt) were compared with mice with deletion of $\mathrm{Cx} 30$ and conditional deletion of $\mathrm{Cx} 43\left(\mathrm{Cx} 30^{-/-}: \mathrm{Cx} 43^{\mathrm{fl} / \mathrm{fl}}\right.$ :hGFAP-Cre, here termed $\mathrm{Cx} 43 \mathrm{ko}$ ). Immunohistochemistry of spinal cord sections identified $\mathrm{Cx} 43$ plaques between astrocytes of $\mathrm{Cx} 43$ wt mice, which were absent in Cx43ko mice (Fig. 1A). Bioluminescence imaging of the exposed spinal cord in rats previously showed that ATP is released from large peritraumatic regions bordering a weight drop injury (Wang et al., 2004). To analyze weight-drop 
A

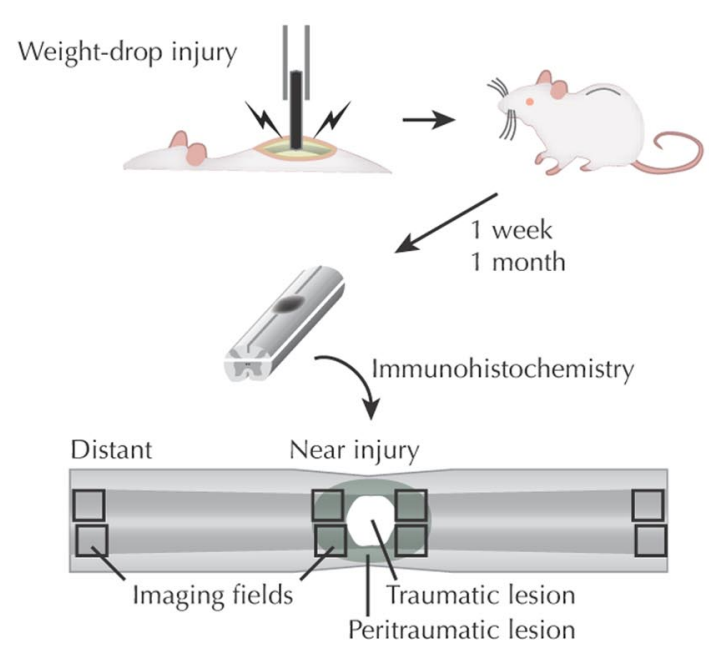

C Iba1
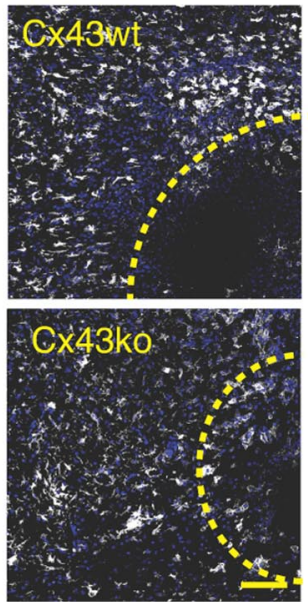

B GFAP
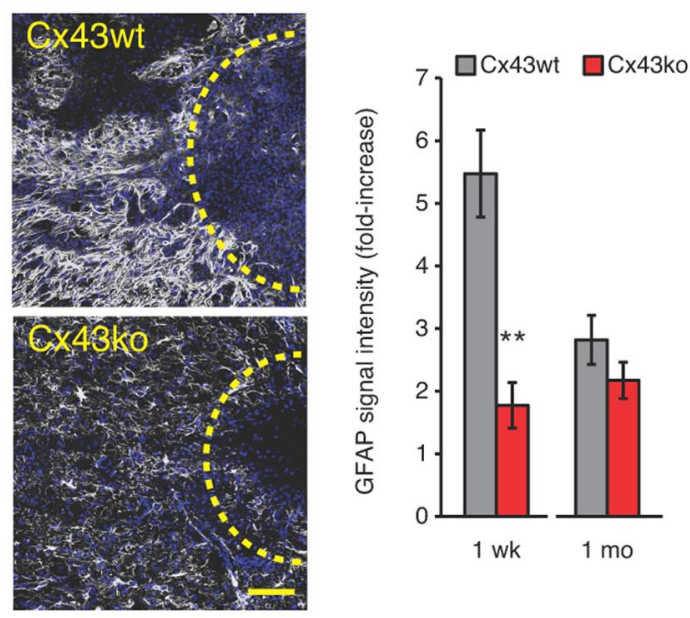

D CD68
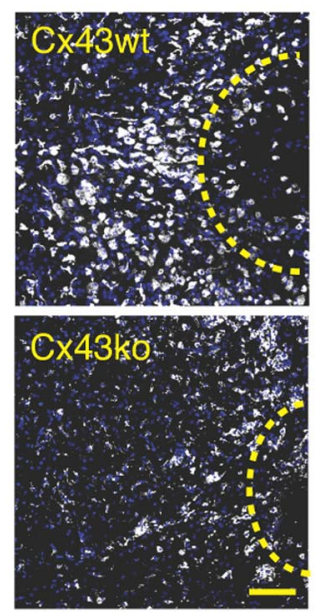

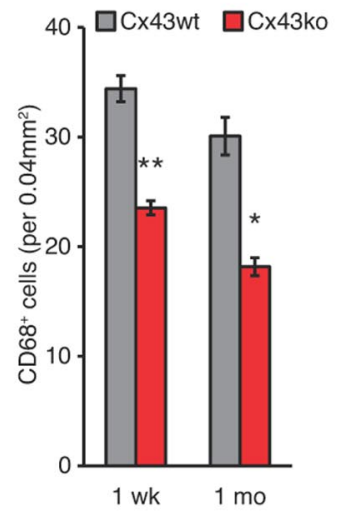

Figure 2. Inflammatory response surrounding the lesion after $S C l$ is less in $(x 43 \mathrm{ko}$ mice. $\boldsymbol{A}, \mathrm{A}$ schematic of experimental procedure. $\boldsymbol{B}-\boldsymbol{D}$, Representative images of spinal cord and quantitation from $\mathrm{Cx} 43$ wt and $\mathrm{Xx43k0} 1$ week after injury: GFAP $(\boldsymbol{B})$, Iba1 (C), and CD68 (D). Blue, DAPl; white, GFAP, Iba1, or CD68. Yellow dotted lines indicate the position of the lesion. GFAP and CD68 were more upregulated after SCl in Cx43wt than in Cx43ko. Scale bar, $100 \mu \mathrm{m} . n=4-6 .{ }^{* *} p<0.01 ;{ }^{*} p<0.05$, Cx43wt versus Cx43ko.

injury and ATP release in mice, we used a $3 \mathrm{~g}$ rod with a $0.5 \mathrm{~mm}$ flat tip dropped from a height of $12.5 \mathrm{~mm}$; extracellular ATP was visualized by light emission resulting from ATP-triggered luciferase activity detected by a liquid nitrogen-cooled CCD camera (Fig. $1 B$ ). Cx43wt mice exhibited, similar to rats, a sustained increase in ATP release from large regions surrounding the traumatic lesion during the observation period of 10-70 min after the traumatic event (Fig. 1C). In contrast, SCI did not trigger distinct zones of high ATP release in Cx43ko mice (Fig. $1 C$ ). The average size of the area with high ATP release was $1.37 \pm 0.20 \mathrm{~mm}^{2}(n=$ $8)$ in Cx43wt and $0.36 \pm 0.09 \mathrm{~mm}^{2}$ in Cx43ko $(n=5 ; p=0.003)$. This observation indicates that $\mathrm{Cx} 43$ plays an important role in ATP release evoked by weight-drop injury of spinal cord.

ATP has previously been implicated as one of several instigators of the innate inflammatory response to traumatic spinal cord injury (Abbracchio et al., 2009). Because there was less ATP release after SCI in Cx43ko mice, we examined whether deletion of $\mathrm{Cx} 43$ also reduced post-traumatic inflammation. Spinal cords 1 week or 1 month after SCI were assessed for reactive astrogliosis based on immunolabeling of GFAP (Fig. 2A). At 1 week, there was a $5.5 \pm 0.7$-fold increase of GFAP immunofluorescent signal in Cx43wt mice close to the traumatic lesion $(n=6)$ compared with tissue distant from the injury. In contrast, $\mathrm{Cx} 43 \mathrm{ko}$ mice exhibited only a $1.8 \pm 0.4$-fold $(n=4)$ elevation of GFAP around the lesion ( $p=0.004$; Cx43wt vs Cx43ko) (Fig. 2 B). At 1 month after injury, GFAP immunoreactivity close to the lesion fell to $2.8 \pm 0.4(n=4)$ times the level in distant tissue in Cx43wt, whereas this ratio in Cx43ko remained unchanged $(2.2 \pm 0.3-$ fold; $n=4)(p=0.248$; Cx43wt vs Cx43ko). Ibal has been implicated in the activation and motility of microglia/macrophages. The Ibal immunofluorescence around the lesion was elevated at both 1 week and 1 month without significant difference between $\mathrm{Cx} 43$ wt and Cx43ko ( $p>0.5$ ) (Fig. $2 C$ ). In contrast, when activated microglia were counted by labeling for CD68, a lysosomal protein expressed by cells of the monocytemacrophage lineage, more CD68-positive cells were observed in Cx43wt than in Cx43ko at both 1 week and 1 month after injury (Fig. 2D). Thus, deletion of $\mathrm{Cx} 43$ in astrocytes reduced acute astrogliosis and microgliosis, which is consistent with the activation of astrocytes and microglial cells at least in part by ATP release from astrocytes.

Because deletion of Cx43 significantly prevented injuryinduced increase in GFAP and CD68, traditional indicators of inflammation, we assessed functional recovery. One week after 

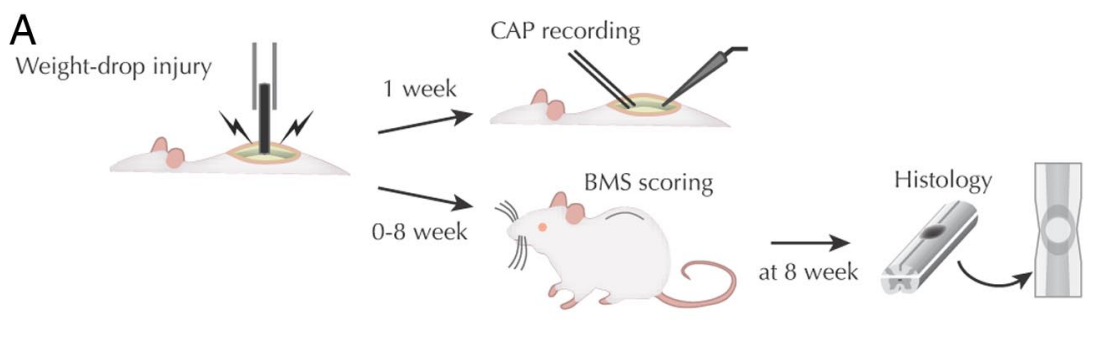
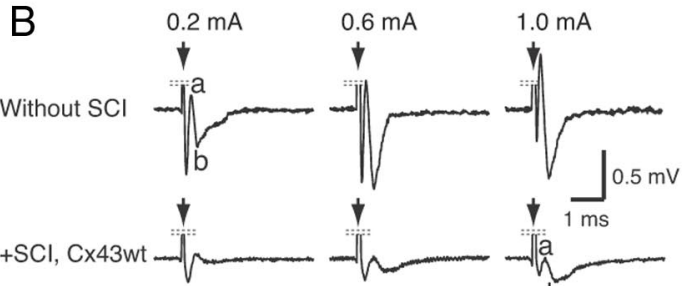

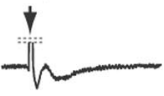<smiles>[131In][131In]</smiles>
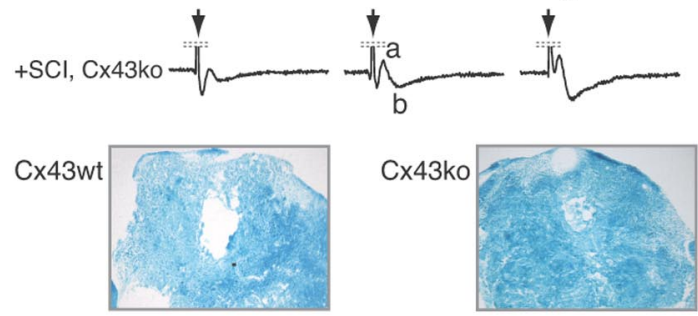

D

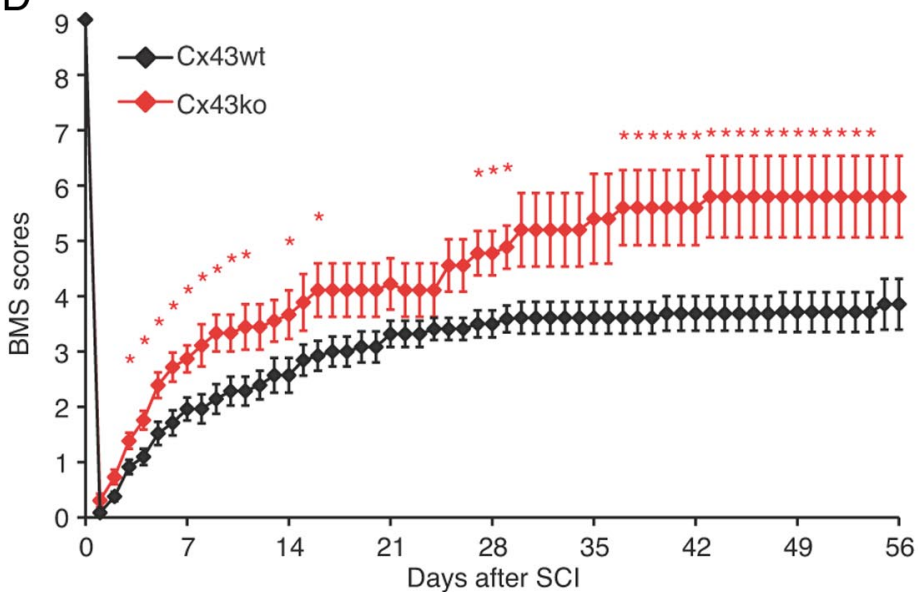

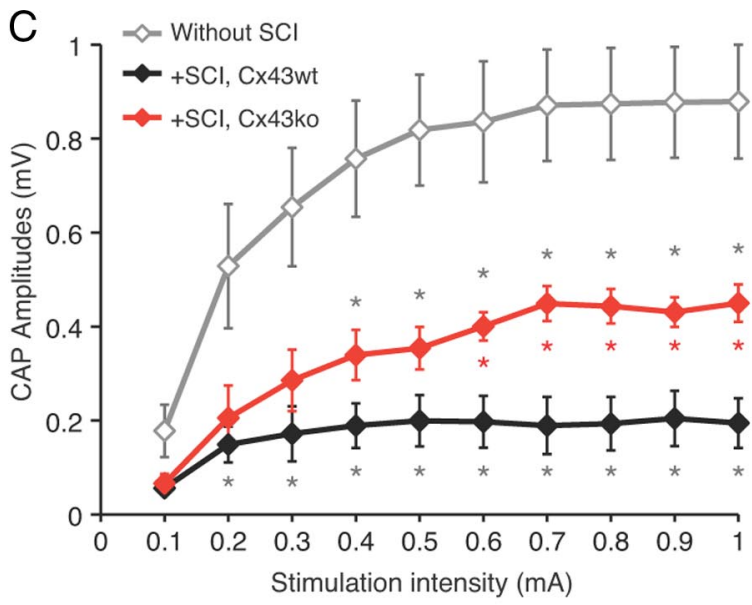

$\mathrm{E}$

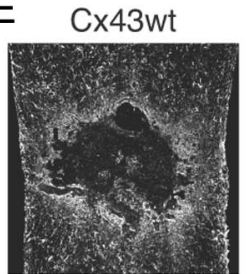

Cx43ko
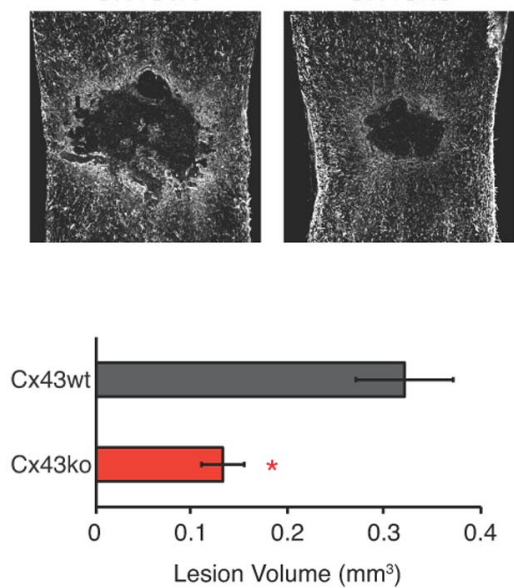

Figure 3. Functional recovery after $S C \mathrm{l}$ is facilitated in $\mathrm{X} 43 \mathrm{k}$ o mice. $A$, A schematic of experimental procedure. $\boldsymbol{B}$, Top, Representative tracings of CPAs in spinal cord caudal to the lesion in response to stimulation on the rostral side in $(x 43$ wt with injury $(+S C I)$, Cx43ko with injury $(+S C l) 1$ week after lesioning, and sham control without SCl. No difference was observed between $(x 43 w t$ and $\mathrm{Cx} 43 \mathrm{ko}$ without $\mathrm{SCl}(p>0.2)$. A large spike by the stimulation artifact was removed from the traces. Bottom, Luxol Fast Blue-stained dorsal column of spinal cord at the lesion center 1 week after the injury in $C x 43$ wt and $C x 43 \mathrm{ko}$. C, A summary histogram of CAP amplitudes against stimulation intensity in $\left(x 43\right.$ wt with injury, $\left(x 43 \mathrm{k} 0\right.$ with injury, and sham control without injury $(n=6)$. ${ }^{*} p<$ 0.017, compared with sham (gray) or between $(x 43 \mathrm{wt}$ and $(x 43 \mathrm{ko}$ (red). $D$, Functional recovery evaluated by BMS locomotor rating, showing improved recovery in $(x 43 \mathrm{ko}(n=5-26)$ compared with Cx43wt ( $n=7-29)$. Score at day 0 was measured just before the injury. ${ }^{*} p<0.05$. E, Top, GFAP immunostaining images of spinal cords 8 weeks after injury. Bottom, A summary histogram of traumatic lesion size in Cx43wt $(n=8)$ and $\mathrm{x} 43 \mathrm{ko}(n=6)$ spinal cord. ${ }^{*} p<0.05$.

injury CAPs that propagated rostro-caudally across the lesion (Fig. 3A) were much smaller than in uninjured Cx43wt control, but larger in Cx43ko than in Cx43wt (Fig. 3B). With 1-mA stimulation of Cx43wt cords, CAP amplitudes were $0.878 \pm 0.121 \mathrm{mV}$ without SCI and $0.195 \pm 0.053 \mathrm{mV}$ at 1 week after SCI $(n=6 ; p<$ 0.01). Cx43ko also showed a reduction of CAP amplitude after spinal cord injury, but amplitudes were larger than in $\mathrm{Cx} 43 \mathrm{wt}$. At 1 -mA stimulation, the CAP was $\sim 2.3$-fold greater in $\mathrm{Cx} 43 \mathrm{ko}$ SCI than in Cx43wt SCI $(0.450 \pm 0.040 \mathrm{mV} ; n=6$; $p<0.05)$ (Fig. $3 C$ ). Luxol Fast Blue staining showed that $12.1 \pm 1.8 \%$ of dorsal white matter myelin was preserved at the site of lesion in Cx43wt, explaining why the CAP was not completely abolished by SCI (Qiao et al., 2006), whereas Cx43ko showed significantly more staining at the dorsal column ( $42.6 \pm 1.8 \% ; n=3-5 ; p<0.001)$ (Fig. $3 B$ ). Thus, by this measure $\mathrm{Cx} 43 \mathrm{ko}$ exhibited a greater preservation of spinal cord conduction than $\mathrm{Cx} 43 \mathrm{wt}$ after a similar traumatic injury. Deletion of $\mathrm{Cx} 43$ also promoted faster recovery of locomotor function after SCI. In blinded analysis using the BMS for locomotion, Cx43ko achieved (for the most part significantly) higher BMS scores starting from $3 \mathrm{~d}$ after the injury throughout the evaluation period of 8 weeks, reaching a score of $5.8 \pm 0.7$ corresponding to consistent hindlimb plantar stepping 
with some coordination $(n=5)$ (Fig. 3D). Differences that appeared in a rather early phase after the injury may suggest that the structural injury is also less severe in Cx43ko mice. The recovery was near maximal after 6 weeks. In contrast, $\mathrm{Cx} 43 \mathrm{wt}$ recovered to $3.5 \pm 0.2$ at 4 weeks $(n=11)$ and never reached a score of 4.0 during the recovery period (Fig. 3D). At 8 weeks most of the Cx43wt exhibited plantar placing of the paw, but no plantar stepping.

The volume of the traumatic lesion was evaluated in the same animals. In Cx43wt the volume was $0.32 \pm 0.05 \mathrm{~mm}^{3}(n=8)$, whereas in Cx43ko the volume was only $0.13 \pm 0.02 \mathrm{~mm}^{3}(n=6$; $p=0.01$ ) (Fig. 3E). Thus, the recordings of CAPs at 1 week, assessment of locomotor recovery over 8 weeks, and lesion size at 8 weeks all suggest that deletion of $\mathrm{Cx} 43$ reduced the severity of traumatic injury and improved recovery.

\section{Discussion}

Previous rat studies showed that SCI causes excessive and sustained ATP release from peritraumatic regions and activation of P2RX7 contributes to reactive changes in both astrocytes and microglial cells as well as neuronal injury (Wang et al., 2004; Cotrina and Nedergaard, 2009; Peng et al., 2009). In this study, we show that expression of $\mathrm{Cx} 43$ in astrocytes plays a key role in post-traumatic release of ATP. Bioluminescence imaging of the exposed spinal cord demonstrated that weight-drop injury caused a sharp increase in ATP release from large peritraumatic regions in Cx43wt mice, but in Cx43ko mice the area of posttraumatic ATP release was significantly smaller (Fig. 1). Moreover, deletion of $\mathrm{Cx} 43$ decreased the inflammatory response to $\mathrm{SCI}$ and suppressed astrogliosis and microgliosis as well as tissue loss (Figs. $2 B-D, 3 E, F$ ). Furthermore, Cx43ko mice recovered motor functions significantly faster and to a greater extent than Cx43wt littermates after SCI (Fig. 3D).

$\mathrm{Cx} 43$ expression is upregulated in regions neighboring traumatic lesions in spinal cord (Theriault et al., 1997; Cronin et al., 2008). The neuroprotective effect of deleting $\mathrm{Cx} 43$ likely involves multiple processes that involve hemichannels, gap junctions, or both. Lack of $\mathrm{Cx} 43$ hemichannels is expected to reduce leakage of cytosolic small molecules, including ATP from astrocytes located in peritraumatic regions, and lack of cell-cell channels would reduce passage of these molecules from neighboring cells, thereby improving astrocytic survival (Cotrina et al., 1998; Parpura et al., 2004). In turn, viable astrocytes would better support neuronal survival and counteract delayed neuronal loss (Faulkner et al., 2004). The suppression of post-traumatic ATP release would reduce ATP-mediated excitotoxic death of neurons and oligodendrocytes by activation of P2RX7s (Wang et al., 2004) and aggravation of secondary injury. P2RX7s are also expressed by microglial cells and infiltrating leukocytes (Collo et al., 1997) and are linked to release of proinflammatory cytokines, including IL-1 $\beta$ (Ferrari et al., 2006). Cytokines are essential parts of the innate inflammatory response and aggravate excitotoxic actions on neurons and oligodendrocytes (Acarin et al., 2000). Finally, gap junctions have been shown to contribute to secondary injury by passage of proapoptotic compounds from dying to otherwise viable gap junction-coupled cells (Lin et al., 1998). Because deletion of Cx43 effectively uncouples astrocytes, it is possible that "bystander death" is reduced and functional recovery thereby improved in $\mathrm{Cx} 43$ knockout mice and possibly more so in our $\mathrm{Cx} 30^{-1-}: \mathrm{Cx} 43^{\mathrm{fl} / \mathrm{fl}}: \mathrm{hGFAP}-\mathrm{Cre}$ mice. Moreover, deletion of $\mathrm{Cx} 43$ affects the expression of multiple other genes (Naus et al., 2000; Iacobas et al., 2004). Thus, it is plausible that, although Cx43 hemichannels provide a direct conduit for ATP release, $\mathrm{Cx} 43$ deletion indirectly reduces ATP release.

Our study contributes to the current revision of mechanisms involved in the innate response to tissue injury. Traditionally it was thought that microglial cells were the first line of defense and microglial cells initiated post-traumatic inflammation by release of cytokines and other proinflammatory agents. However, in vivo imaging has shown that purinergic receptor activation is both necessary and sufficient for movement of microglial cell processes in response to local laser injury or ATP injection (Davalos et al., 2005; Nimmerjahn et al., 2005). Microglial cells express several purinergic receptors (Koizumi et al., 2007). Deletion or pharmacological blockage of P2RY12 reduces or eliminates movement of microglial cell processes (Haynes et al., 2006; Tozaki-Saitoh et al., 2008), whereas P2RY6 activation is a key determinant of phagocytosis (Koizumi et al., 2007). Moreover, P2RX7 activation triggers maturation and secretion of IL- $1 \beta$ from microglial cells (Di Virgilio et al., 1999). The observation that deletion of $\mathrm{Cx} 43$ reduces post-traumatic ATP release, as well as microglial cell activation, supports the idea that astrocytes are first to sense injury and activation of microglial cells is triggered by astrocytic ATP release. In cultures spinal astrocytes respond to FGF-1 by the release of ATP, which activates purinergic receptors, leading to the opening of pannexin hemichannels and ultimately Cx43 hemichannels (Garré et al., 2010).

An important aspect of the study was that functional recovery occurred significantly faster in $\mathrm{Cx} 43 \mathrm{ko}$ mice consistent with the smaller traumatic lesions noted in these animals (Fig. 3). The fact that $\mathrm{Cx} 43 \mathrm{ko}$ mice displayed significantly better motor functions as early as $3 \mathrm{~d}$ after injury suggests that deletion of $\mathrm{Cx} 43$ directly protected dorsal tracts, rather than promoted neuronal regrowth. One possible explanation is that the lack of $\mathrm{Cx} 43$ reduced the acute inflammatory response, including tissue swelling and secondary ischemic loss of white-matter tracts. Another possibility is that P2RX7 activation in oligodendrocytes directly contributes to loss of myelin and reduction in action potential amplitude due to exposure to ATP (Matute et al., 2007). Significant recovery of function might then be associated with remyelination (Qiao et al., 2006).

Cx43 may represent a novel target for reducing the severity of traumatic spinal cord injury. Although the neuroprotective effect of $\mathrm{Cx} 43$ deletion may involve multiple pathways, our analysis suggests that a reduction in excessive ATP release from peritraumatic areas reduces the post-traumatic inflammatory response that negatively affects recovery.

\section{References}

Abbracchio MP, Burnstock G, Verkhratsky A, Zimmermann H (2009) Purinergic signalling in the nervous system: an overview. Trends Neurosci 32:19-29.

Acarin L, González B, Castellano B (2000) Neuronal, astroglial and microglial cytokine expression after an excitotoxic lesion in the immature rat brain. Eur J Neurosci 12:3505-3520.

Basso DM, Fisher LC, Anderson AJ, Jakeman LB, McTigue DM, Popovich PG (2006) Basso Mouse Scale for locomotion detects differences in recovery after spinal cord injury in five common mouse strains. J Neurotrauma 23:635-659.

Bennett MV, Contreras JE, Bukauskas FF, Sáez JC (2003) New roles for astrocytes: gap junction hemichannels have something to communicate. Trends Neurosci 26:610-617.

Bethea JR (2000) Spinal cord injury-induced inflammation: a dual-edged sword. Prog Brain Res 128:33-42.

Collo G, Neidhart S, Kawashima E, Kosco-Vilbois M, North RA, Buell G (1997) Tissue distribution of the P2X7 receptor. Neuropharmacology 36:1277-1283. 
Cotrina ML, Nedergaard M (2009) Physiological and pathological functions of P2X7 receptor in the spinal cord. Purinergic Signal 5:223-232.

Cotrina ML, Lin JH, Alves-Rodrigues A, Liu S, Li J, Azmi-Ghadimi H, Kang J, Naus CC, Nedergaard M (1998) Connexins regulate calcium signaling by controlling ATP release. Proc Natl Acad Sci U S A 95:15735-15740.

Cronin M, Anderson PN, Cook JE, Green CR, Becker DL (2008) Blocking connexin 43 expression reduces inflammation and improves functional recovery after spinal cord injury. Mol Cell Neurosci 39:152-160.

Davalos D, Grutzendler J, Yang G, Kim JV, Zuo Y, Jung S, Littman DR, Dustin ML, Gan WB (2005) ATP mediates rapid microglial response to local brain injury in vivo. Nat Neurosci 8:752-758.

Di Virgilio F, Sanz JM, Chiozzi P, Falzoni S (1999) The P2Z/P2X7 receptor of microglial cells: a novel immunomodulatory receptor. Prog Brain Res 120:355-368.

Faulkner JR, Herrmann JE, Woo MJ, Tansey KE, Doan NB, Sofroniew MV (2004) Reactive astrocytes protect tissue and preserve function after spinal cord injury. J Neurosci 24:2143-2155.

Ferrari D, Pizzirani C, Adinolfi E, Lemoli RM, Curti A, Idzko M, Panther E, Di Virgilio F (2006) The P2X7 receptor: a key player in IL-1 processing and release. J Immunol 176:3877-3883.

Garré JM, Retamal MA, Cassina P, Barbeito L, Bukauskas FF, Sáez JC, Bennett MV, Abudara V (2010) FGF-1 induces ATP release from spinal astrocytes in culture and opens pannexin and connexin hemichannels. Proc Natl Acad Sci U S A 107:22659-22664.

Haynes SE, Hollopeter G, Yang G, Kurpius D, Dailey ME, Gan WB, Julius D (2006) The P2Y12 receptor regulates microglial activation by extracellular nucleotides. Nat Neurosci 9:1512-1519.

Iacobas DA, Scemes E, Spray DC (2004) Gene expression alterations in connexin null mice extend beyond the gap junction. Neurochem Int 45:243-250.

Koizumi S, Shigemoto-Mogami Y, Nasu-Tada K, Shinozaki Y, Ohsawa K, Tsuda M, Joshi BV, Jacobson KA, Kohsaka S, Inoue K (2007) UDP acting at P2Y6 receptors is a mediator of microglial phagocytosis. Nature 446:1091-1095

Lin JH, Weigel H, Cotrina ML, Liu S, Bueno E, Hansen AJ, Hansen TW, Goldman S, Nedergaard M (1998) Gap-junction-mediated propagation and amplification of cell injury. Nat Neurosci 1:494-500.

Lin JH, Lou N, Kang N, Takano T, Hu F, Han X, Xu Q, Lovatt D, Torres A, Willecke K, Yang J, Kang J, Nedergaard M (2008) A central role of connexin 43 in hypoxic preconditioning. J Neurosci 28:681-695.

Matute C, Torre I, Pérez-Cerdá F, Pérez-Samartin A, Alberdi E, Etxebarria E, Arranz AM, Ravid R, Rodríguez-Antigüedad A, Sánchez-Gómez M, Domercq M (2007) P2X(7) receptor blockade prevents ATP excitotoxicity in oligodendrocytes and ameliorates experimental autoimmune encephalomyelitis. J Neurosci 27:9525-9533.

Naus CC, Bond SL, Bechberger JF, Rushlow W (2000) Identification of genes differentially expressed in C6 glioma cells transfected with connexin43. Brain Res Brain Res Rev 32:259-266.

Nimmerjahn A, Kirchhoff F, Helmchen F (2005) Resting microglial cells are highly dynamic surveillants of brain parenchyma in vivo. Science 308:1314-1318

Parpura V, Scemes E, Spray DC (2004) Mechanisms of glutamate release from astrocytes: gap junction "hemichannels," purinergic receptors and exocytotic release. Neurochem Int 45:259-264.

Peng W, Cotrina ML, Han X, Yu H, Bekar L, Blum L, Takano T, Tian GF, Goldman SA, Nedergaard M (2009) Systemic administration of an antagonist of the ATP-sensitive receptor P2X7 improves recovery after spinal cord injury. Proc Natl Acad Sci U S A 106:12489-12493.

Popovich PG, Longbrake EE (2008) Can the immune system be harnessed to repair the CNS? Nat Rev Neurosci 9:481-493.

Qiao F, Atkinson C, Song H, Pannu R, Singh I, Tomlinson S (2006) Complement plays an important role in spinal cord injury and represents a therapeutic target for improving recovery following trauma. Am J Pathol 169:1039-1047

Sekhon LH, Fehlings MG (2001) Epidemiology, demographics, and pathophysiology of acute spinal cord injury. Spine (Phila Pa 1976) 26:S2-S12.

Theis M, de Wit C, Schlaeger TM, Eckardt D, Krüger O, Döring B, Risau W, Deutsch U, Pohl U, Willecke K (2001) Endothelium-specific replacement of the connexin 43 coding region by a lacZ reporter gene. Genesis 29:1-13.

Theis M, Jauch R, Zhuo L, Speidel D, Wallraff A, Döring B, Frisch C, Söhl G, Teubner B, Euwens C, Huston J, Steinhäuser C, Messing A, Heinemann U, Willecke K (2003) Accelerated hippocampal spreading depression and enhanced locomotory activity in mice with astrocyte-directed inactivation of connexin43. J Neurosci 23:766-776.

Theriault E, Frankenstein UN, Hertzberg EL, Nagy JI (1997) Connexin43 and astrocytic gap junctions in the rat spinal cord after acute compression injury. J Comp Neurol 382:199-214.

Tozaki-Saitoh H, Tsuda M, Miyata H, Ueda K, Kohsaka S, Inoue K (2008) $\mathrm{P} 2 \mathrm{Y} 12$ receptors in spinal microglia are required for neuropathic pain after peripheral nerve injury. J Neurosci 28:4949-4956.

Wallraff A, Köhling R, Heinemann U, Theis M, Willecke K, Steinhäuser C (2006) The impact of astrocytic gap junctional coupling on potassium buffering in the hippocampus. J Neurosci 26:5438-5447.

Wang X, Arcuino G, Takano T, Lin J, Peng WG, Wan P, Li P, Xu Q, Liu QS, Goldman SA, Nedergaard M (2004) P2X7 receptor inhibition improves recovery after spinal cord injury. Nat Med 10:821-827. 